\title{
RADIOCARBON AMS DATA ANALYSIS: FROM MEASURED ISOTOPIC RATIOS TO ${ }^{14} \mathrm{C}$ CONCENTRATIONS
}

\author{
Ugo Zoppi \\ Accium BioSciences Inc., 550 17th Avenue, Suite 550, Seattle, Washington 98122, USA. Email: uzoppi@acciumbio.com.
}

\begin{abstract}
Radiocarbon accelerator mass spectrometry (AMS) measurements are always carried out relative to internationally accepted standards with known ${ }^{14} \mathrm{C}$ activities. The determination of accurate ${ }^{14} \mathrm{C}$ concentrations relies on the fact that standards and unknown samples must be measured under the same conditions. When this is not the case, data reduction is either performed by splitting the collected data set into subsets with consistent measurement conditions or by applying correction factors.
\end{abstract}

This paper introduces a mathematical framework that exploits the intrinsic variability of an AMS system by combining arbitrary measurement parameters into a normalization function. This novel approach allows the en-masse reduction of large data sets by providing individual normalization factors for each data point. Both general features and practicalities necessary for its efficient application are discussed.

\section{INTRODUCTION}

As part of the unrelenting quest for more accurate radiocarbon dates, many papers dealing with accelerator mass spectrometry (AMS) ${ }^{14} \mathrm{C}$ data analysis and accuracy have been published. Donahue et al. (1990), Mook and van der Plicht (1999), and McNichol et al. (2001) discuss the essential equations and conventions. Meanwhile, Scott et al. (2007) present a detailed review of relevant statistical issues such as reproducibility and uncertainty. Hua et al. (2004) discuss analysis of small-mass samples and corresponding processed blanks corrections. These papers have been complemented by a wide range of more technically oriented investigations aimed at identifying the most likely parameters that could directly affect the accuracy of ${ }^{14} \mathrm{C}$ AMS measurements. For example, current-dependent fractionation due to space charges and terminal loading has been reported by Bronk Ramsey and Hedges (1994, 1997) and Steier et al. (2004). In Puchegger et al. (2000), the effect of target wheel eccentricity has been considered. Tumey et al. (2004) discuss a time-dependent correction to compensate for machine drifts. Finally, different filtering techniques have been introduced for the identification and rejection of spurious data (Schneider et al. 1994; Séguin et al. 1994).

This paper presents a new ${ }^{14} \mathrm{C}$ data reduction formalism that can be used to investigate all potential dependencies and, if necessary, correct the entire data set for them. In particular, it has the capability to reveal correlations between seemingly unrelated parameters. For example, mass-dependent fractionation and time drift could be combined into a single normalization function, providing more accurate results when compared to values obtained considering only 1 of the 2 effects.

\section{THE EFFICIENCY FUNCTION}

All ${ }^{14} \mathrm{C}$ reference materials are characterized by 2 values, a fraction of modern $F_{S t d}$, which has been normalized to ${ }^{13} \delta=-25 \%$, and an actual value of ${ }^{13} \delta_{\text {Std }}$. Donahue et al. (1990) demonstrated that when the HOxII standard material is being used, the fraction of modern of an unknown sample $F_{U n k}$ is given by 


$$
F_{U n k}=\frac{\left(\frac{0.975}{1+{ }^{13} \delta_{U n k}}\right) \cdot\left(\frac{{ }^{14} \mathrm{C}}{{ }^{13} \mathrm{C}}\right)_{U n k}}{0.7404 \cdot\left(\frac{{ }^{14} \mathrm{C}}{{ }^{13} \mathrm{C}}\right)_{\text {HOxII }}}
$$

This formula can be generalized for use with different standards:

$$
F_{U n k}=\frac{\left(\frac{0.975}{1+{ }^{13} \delta_{U n k}}\right)\left(\frac{{ }^{14} \mathrm{C}}{{ }^{13} \mathrm{C}}\right)_{U n k}}{\left(\frac{0.975}{1+{ }^{13} \delta_{S t d}}\right)\left(\frac{{ }^{14} \mathrm{C}}{{ }^{13} \mathrm{C}}\right)_{S t d}} F_{S t d}
$$

Numerical values of $F_{S t d}$ and ${ }^{13} \delta_{S t d}$ are summarized in Table 1.

Table 1 Consensus fraction of modern $F_{S t d}$ and ${ }^{13} \delta_{S t d}$ values for commonly used ${ }^{14} \mathrm{C}$ standards.

\begin{tabular}{lllcl}
\hline Name & Material & $F_{\text {Std }}$ & ${ }^{13} \delta_{S t d}(\%)$ & Reference \\
\hline HOxI & Oxalic acid & 1.0398 & -19.0 & Stuiver 1983 \\
HOxII & Oxalic acid & 1.3407 & -17.8 & Stuiver 1983 \\
IAEA-C1 & Marble & 0 & $2.42 \pm 0.33$ & Le Clercq et al. 1998 \\
IAEA-C2 & Chalk & $0.4114 \pm 0.0003$ & $-8.25 \pm 0.31$ & Le Clercq et al. 1998 \\
IAEA-C3 & Paper & $1.2941 \pm 0.0006$ & $-24.91 \pm 0.49$ & Le Clercq et al. 1998 \\
IAEA-C4 & Wood & $0.0002-0.0004$ & $-23.96 \pm 0.62$ & Le Clercq et al. 1998 \\
IAEA-C5 & Wood & $0.2305 \pm 0.0002$ & $-25.49 \pm 0.72$ & Le Clercq et al. 1998 \\
IAEA-C6 & Sucrose & $1.5061 \pm 0.0011$ & $-10.80 \pm 0.47$ & Le Clercq et al. 1998 \\
IAEA-C7 & Oxalic acid & $0.4954 \pm 0.0013$ & $-14.48 \pm 0.13$ & Le Clercq et al. 1998 \\
IAEA-C8 & Oxalic acid & $0.1503 \pm 0.0018$ & $-18.31 \pm 0.23$ & Le Clercq et al. 1998 \\
\hline
\end{tabular}

Accurate determination of $F_{U n k}$ using Equation 2 is possible only when standards and unknown samples are measured under identical conditions. This constraint is obviously never fulfilled and an efficiency function ${ }^{14} \varepsilon(\mathrm{X})$ for the measurement of the ${ }^{14} \mathrm{C} /{ }^{13} \mathrm{C}$ ratio must be introduced. Note that at this moment, no assumptions regarding the characteristics of the efficiency function are necessary. $\mathrm{X}$ stands for an array $\left(x^{1}, x^{2}, \ldots, x^{p}\right)$ of measurement parameters. When ${ }^{14} \varepsilon(\mathrm{X})$ is added to Equation 2, it is clear that

$$
\frac{F_{S t d}}{\left(\frac{0.975}{1+{ }^{13} \delta_{S t d}}\right) \cdot\left(\frac{{ }^{14} \mathrm{C}}{{ }^{13} \mathrm{C}}\right)_{S t d} \cdot{ }^{14} \varepsilon\left(\mathrm{X}_{S t d}\right)}
$$

is a constant and thus 


$$
\frac{1}{{ }^{14} \varepsilon\left(\mathrm{X}_{S t d}\right)} \alpha \frac{\left(\frac{0.975}{1+{ }^{13} \delta_{S t d}}\right)\left(\frac{{ }^{14} \mathrm{C}}{{ }^{13} \mathrm{C}}\right)_{S t d}}{F_{S t d}}
$$

This relationship between efficiency and measured radioisotopic ratios can be used to experimentally derive the shape of $1 /{ }^{14} \varepsilon\left(\mathrm{X}_{S t d}\right)$ and allow accurate interpolation at the $\mathrm{X}_{U n k}$ coordinates corresponding to the measurement of unknown samples. When the proper interpolation procedure has been performed - the simplest case of a flat surface $\left(1 /{ }^{14} \varepsilon=a_{1} x^{1}+a_{2} x^{2}+\ldots+a_{p} x^{p}+a_{p+1}\right)$ including correct error propagation is fully discussed in next section $-F_{U n k}$ is given by

$$
F_{U n k}=\left(\frac{0.975}{1+{ }^{13} \delta_{U n k}}\right)\left(\frac{{ }^{14} \mathrm{C}}{{ }^{13} \mathrm{C}}\right)_{U n k} \cdot{ }^{14} \varepsilon\left(\mathrm{X}_{U n k}\right)
$$

A similar formalism can be employed for the determination of ${ }^{13} \delta_{U n k}$ values. After introducing an additional efficiency function ${ }^{13} \varepsilon(Y)$ for the measurement of the ${ }^{13} \mathrm{C} /{ }^{12} \mathrm{C}$ ratio, it is possible to show that

$$
\frac{1}{{ }^{13} \varepsilon\left(\mathrm{Y}_{s t d}\right)} \alpha \frac{\left(\frac{{ }^{13} \mathrm{C}}{{ }^{12} \mathrm{C}}\right)_{S t d}}{1+{ }^{13} \delta_{S t d}}
$$

Note that the efficiency function ${ }^{14} \varepsilon(\mathrm{X})$ and ${ }^{13} \varepsilon(\mathrm{Y})$ are not required to have the same parameter list. The flat surface interpolation procedure described below can be easily adapted to calculate the parameters of $1 /{ }^{13} \varepsilon=b_{1} y^{1}+b_{2} y^{2}+\ldots+b_{p^{\prime}} y^{p^{\prime}}+b_{p^{\prime}+1}$ and eventually derive measured ${ }^{13} \delta_{\text {Unk }}$ values:

$$
{ }^{13} \delta_{U n k}=\left(\frac{{ }^{13} C}{{ }^{12} C}\right)_{U n k} \cdot{ }^{13} \varepsilon\left(\mathrm{Y}_{U n k}\right)-1
$$

By combining Equations 5 and $7, F_{\text {Unk }}$ can be directly expressed as a function of measured ${ }^{14} \mathrm{C} /{ }^{13} \mathrm{C}$ and ${ }^{13} \mathrm{C} /{ }^{12} \mathrm{C}$ ratios:

$$
F_{U n k}=0.975 \cdot \frac{\left(\frac{{ }^{14} \mathrm{C}}{{ }^{13} \mathrm{C}}\right)_{U n k}}{\left(\frac{{ }^{13} \mathrm{C}}{{ }^{12} \mathrm{C}}\right)_{U n k}} \cdot \frac{\varepsilon\left(X_{U n k}\right)}{{ }^{13} \varepsilon\left(Y_{U n k}\right)}
$$

\section{MULTIDIMENSIONAL FLAT SURFACE FITTING}

It is anticipated, but this is by no means a rule, that a flat surface will be adequate in most data reduction cases. The use of more complex functions could be considered-e.g. to account for the target wheel eccentricity as suggested by Puchegger et al. (2000)_-but is beyond the scope of this paper. 
Measurement of different standards during an AMS experiment provides $N$ data points $\left(x_{i}^{1}, x_{i}^{2}, \ldots, x_{i}^{P}, 1 /{ }^{14} \varepsilon_{i}\right)$. First, a new set of coordinates is introduced. The new origin is placed where the density of measured data points is larger and thus the efficiency function more accurately known:

$$
x_{i}^{\prime k}=x_{i}^{k}-\bar{x}^{-k} \quad(k=1,2, \ldots, P)
$$

and

$$
{ }^{-k}=\frac{\sum_{i=1}^{N} x_{i}^{k}}{N}
$$

The fitting of a flat surface $\left(1 /{ }^{14} \varepsilon=a_{1} x^{\prime 1}+a_{2} x^{\prime 2}+\ldots+a_{p} x^{\prime}+a_{p+1}\right)$ through the measured data points corresponds to finding an approximate solution for the set of linear equations:

$$
\left[\begin{array}{ccccc}
x_{1}^{\prime 1} & x_{1}^{\prime 2} & \ldots & x_{1}^{\prime p} & 1 \\
x_{2}^{\prime 1} & x_{2}^{\prime 2} & \ldots & x_{1}^{\prime p} & 1 \\
\vdots & \vdots & & \vdots & \\
x_{N}^{\prime 1} & x_{N}^{\prime 2} & \ldots & x_{N}^{\prime p} & 1
\end{array}\right] \cdot\left[\begin{array}{c}
a_{1} \\
a_{2} \\
\vdots \\
a_{p+1}
\end{array}\right]=\left[\begin{array}{c}
1 /{ }^{14} \varepsilon_{1} \\
1 /{ }^{14} \varepsilon_{2} \\
\vdots \\
1 /{ }^{14} \varepsilon_{N}
\end{array}\right]
$$

This is achieved by multiplying with the transposed matrix:

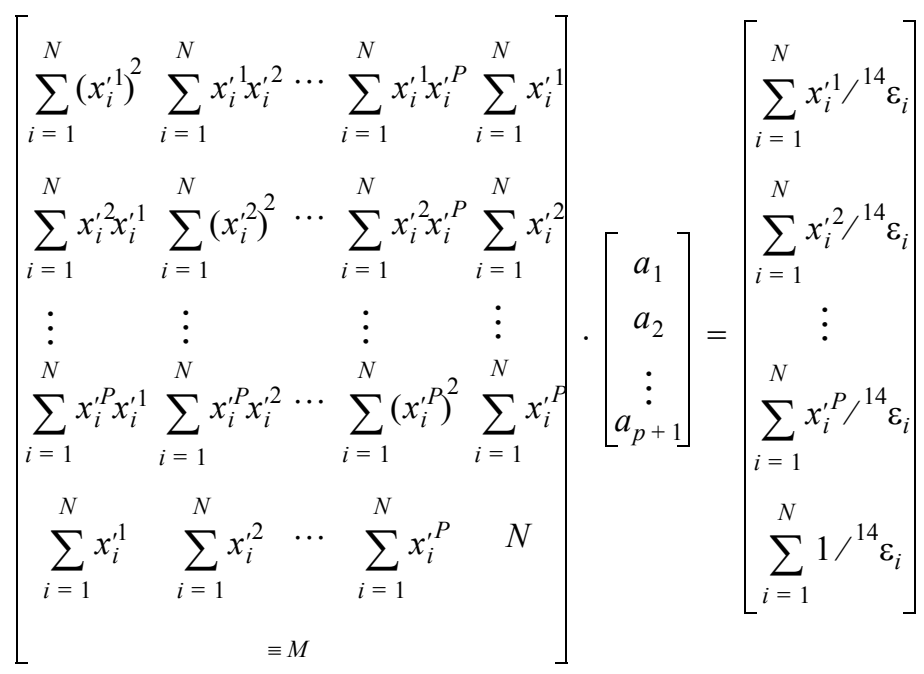

After calculating the inverse matrix $M^{-1}$ (e.g. by means of the Gaussian substitution method), the most likely values for $a_{k}(k=1,2, \ldots, P+1)$ are:

$$
a_{k}=\left(M^{-1}\right)_{k 1} \sum_{i=1}^{N} \frac{x_{i}^{\prime 1}}{14}+\left(M^{-1}\right)_{k 2} \sum_{i=1}^{N} \frac{x_{i}^{\prime 2}}{14} \varepsilon_{i}+\ldots+\left(M^{-1}\right)_{k P} \sum_{i=1}^{N} \frac{x_{i}^{\prime P}}{14} \varepsilon_{i}+\left(M^{-1}\right)_{k P+1} \sum_{i=1}^{N} \frac{1}{14}
$$


If every line in Equation 11 is scaled with the measurement error associated with $1 /{ }^{14} \varepsilon_{i}$, the diagonal elements of the inverse matrix correspond to the first-order approximation of the uncertainties $\sigma^{2}\left(a_{k}\right)$ :

$$
\sigma^{2}\left(a_{k}\right)=\left(M^{-1}\right)_{k k}
$$

In calculating $F_{U n k}$, one must now be careful to do so in the new coordinate system. Note that if no dependencies are observed, the values of all parameters $a_{k}$ are negligible $\left(a_{k} \approx 0\right)$ and the data reduction procedure effectively corresponds to a simple normalization using the global average of all measured standards.

\section{DISCUSSION}

Data analysis software based on the normalization procedure presented above can be straightforwardly developed for all common platforms. Ideally, it will let the user select different parameters and calculate the most likely coefficients of the efficiency function $1 /{ }^{14} \varepsilon=a_{1} x^{1}+a_{2} x^{2}+\ldots+a_{P} x^{P}+$ $a_{P+1}$ and $1 /{ }^{13} \varepsilon=b_{1} y^{1}+b_{2} y^{2}+\ldots+b_{P^{\prime}} y^{P^{\prime}}+b_{P^{\prime}+1}$. A graphical display and/or the more formal $R^{2}$ correlation coefficient could provide confirmation that the selected parameters are indeed relevant.

The real strength of such a data reduction system is its versatility. For example, provided the relevant data regarding the condition of the spectrometer have been collected, one could switch from a "time-current" correction to a "detector deadtime-sample mass-sputtering time" correction with a simple mouse click. The software has merely to recalculate the elements of matrix $M$ in Equation 12 and invert it. This requires very little computing time, allowing for real-time assessment options.

It is now up to the user, knowing the idiosyncrasies of the AMS system being used, to make educated guesses regarding the most relevant parameters affecting the measurement accuracy. In general, there is no need to simultaneously consider more than 2 or 3 different parameters. Increasing the number of dimensions would require a corresponding increase in measurement points through which to fit the efficiency function. The experience collected at Accium BioSciences with the NEC 1.5SDH-1 Pelletron AMS system (Zoppi et al. 2007) suggests that, if the reproducibility of the Accium AMS system can be increased, it can be done using a " ${ }^{13} \mathrm{C}$ current-measurement time" correction. Such an approach becomes essential when ${ }^{13} \mathrm{C}$-enriched carbon carrier is added to biological samples to simultaneously determine total carbon masses and ${ }^{14} \mathrm{C}$ concentrations (Zoppi and Arjomand 2009).

\section{OUTLOOK}

The normalization method presented here can easily be adapted to include all radioisotopes commonly measured by AMS. After establishing the relationship between efficiency, measured ratios for standards, and their nominal value, the determination of the shape of the efficiency function can proceed as described.

\section{CONCLUSIONS}

A new method for ${ }^{14} \mathrm{C}$ data analysis has been presented. It allows the simultaneous use of different standards with different $F_{S t d}$ and ${ }^{13} \delta_{S t d}$ values and employs the intrinsic variability of an AMS system to determine individual normalization factors for each unknown. Due to its versatility, it provides an excellent tool to investigate and identify the parameters most likely to directly affect the accuracy of ${ }^{14} \mathrm{C}$ measurements. 


\section{REFERENCES}

Bronk Ramsey C, Hedges REM. 1994. Carbon dioxide sputter source development at Oxford. Nuclear Instruments and Methods in Physics Research B 92(1-4): $100-4$.

Bronk Ramsey C, Hedges REM. 1997. Hybrid ion sources: radiocarbon measurements from microgram to milligram. Nuclear Instruments and Methods in Physics Research B 123(1-4):539-45.

Donahue DJ, Linick TW, Jull AJT. 1990. Isotope-ratio and background corrections for accelerator mass spectrometry radiocarbon measurements. Radiocarbon 32(2):135-42.

Hua Q, Zoppi U, Williams AA, Smith AM. 2004. Smallmass AMS radiocarbon analysis at ANTARES. $\mathrm{Nu}$ clear Instruments and Methods in Physics Research B 223-224:284-92.

Le Clercq M, van der Plicht J, Gröning M. 1998. New ${ }^{14} \mathrm{C}$ reference materials with activities of 15 and $50 \mathrm{pMC}$. Radiocarbon 40(1):295-7.

Mook W, van der Plicht J. 1999. Reporting ${ }^{14} \mathrm{C}$ activities and concentrations. Radiocarbon 41(3):227-9.

McNichol AP, Jull AJT, Burr GS. 2001. Converting AMS data to radiocarbon values: considerations and conventions. Radiocarbon 43(2A):313-20.

Puchegger S, Rom W, Steier P. 2000. Automated evaluation of ${ }^{14} \mathrm{C}$ AMS measurements. Nuclear Instruments and Methods in Physics Research B 172(1-4):274-80.

Schneider RJ, Jones GA, McNichol AP, von Reden KF, Elder KL, Huang K, Kessel ED. 1994. Methods for data screening, flagging and error analysis at the National Ocean Sciences AMS Facility. Nuclear Instruments and Methods in Physics Research B 92(1-4): 172-5.

Scott EM, Cook GT, Naysmith P. 2007. Error and uncertainty in radiocarbon measurements. Radiocarbon 49(2):427-40.

Séguin FH, Schneider RJ, Jones GA, von Reden KF. 1994. Optimized data analysis for AMS radiocarbon dating. Nuclear Instruments and Methods in Physics Research B 92(1-4):176-81.

Steier P, Dellinger F, Kutschera W, Priller A, Rom W, Wild EM. 2004. Pushing the precision limit of ${ }^{14} \mathrm{C}$ AMS. Radiocarbon 46(1):5-16.

Stuiver M. 1983. International agreements and the use of the new oxalic acid standards. Radiocarbon 25(2): 793-5.

Tumey SJ, Grabowski KS, Knies DL, Mignerey AC. 2004. Radiocarbon data collection, filtering and analysis at the NRL TEAMS facility. Nuclear Instruments and Methods in Physics Research B 223-224:216-20.

Zoppi U, Arjomand A. 2009. Simultaneous AMS determination of ${ }^{14} \mathrm{C}$ content and total carbon mass in biological samples. Nuclear Instruments and Methods in Physics Research B. doi:10.1016/j.nimb.2009.10.159.

Zoppi U, Crye J, Song Q, Arjomand A. 2007. Performance evaluation of the new AMS system at Accium BioSciences. Radiocarbon 49(1):173-82. 